\title{
Controlling the distribution of oxygen functionalities on GO and utilization of PEDOT:PSS-GO composite as hole injection layer of a solution processed blue OLED
}

\author{
Halide Diker $^{\text {a, }{ }^{* *}, \text { Gamze Belkıs Durmaz }}{ }^{\text {a }}$, Hakan Bozkurt ${ }^{a}$, Fatih Yeşil ${ }^{a}$, \\ Canan Varlikli a, b, * \\ a Ege University, Solar Energy Institute, 35100, Bornova, Izmir, Turkey \\ b Izmir Institute of Technology, Department of Photonics, 35430, Urla, Izmir, Turkey
}

\section{A R T I C L E I N F O}

\section{Article history:}

Received 21 December 2016

Received in revised form

2 February 2017

Accepted 8 February 2017

Available online 12 February 2017

\section{Keywords:}

Graphene oxide

Particle size

Chemically oxidized graphene

PEDOT:PSS-GO composite

Organic light emitting diode

\begin{abstract}
A B S T R A C T
Graphene oxide (GO) was synthesis by Tour method. Particle size distribution effects of raw graphite on the resulting structural, morphological, optical and electrical properties of GO samples and their poly(3,4-ethylenedioxythiophene):poly(styrenesulfonate) (PEDOT:PSS) composites are studied for the graphite particle distributions of $<150,45-75$ and $25-45 \mu \mathrm{m}$. It is determined that particle size of raw graphite have an impact on oxidation degree, the chemical nature of oxygen functional groups on GO and it also affects the lateral size of obtained GO.

PEDOT:PSS-GO composites are utilized as hole injection layer (HIL) in a solution process blue organic light emitting diode. Presence of GO caused negative differential resistance (NDR) and NDR intensity was decreased with the decrease in lateral size of GO, increase in the graphite particle size and carboxyl\% of obtained GO. All PEDOT:PSS-GO composite based devices presented better performance than the bare PEDOT:PSS based reference device. The maximum luminous and external quantum efficiency values of the device that contain HIL of PEDOT:PSS-GO(150) were more than $40 \%$ and $50 \%$ higher than that of the reference, respectively. Two folds of increase in these performance values were able to be reached with the concentration optimization of GO/150 in PEDOT:PSS.
\end{abstract}

(C) 2017 Elsevier B.V. All rights reserved.

\section{Introduction}

Graphene is known as a single atom thick sheet of graphite which has $\mathrm{sp}^{2}$ hybridized carbon atoms within the hexagonal structure [1]. This hybridization leads to high electron delocalization on the carbon layer and brings superior electronic properties into graphene [1,2]. Graphene has gained much attention in various application areas such as organic photonic systems (OLEDs, OPVs, OFEDs, photo-sensors), fuel cells, capacitors, catalysis, biomedicines and composite materials due to its extraordinary mechanical, thermal, electrochemical, magnetic and electronic properties [3-16].

\footnotetext{
* Corresponding author. Izmir Institute of Technology, Department of Photonics, 35430, Urla, Izmir, Turkey.

** Corresponding author.

E-mail addresses: dikerhalide@gmail.com (H. Diker), cananvarlikli@iyte.edu.tr (C. Varlikli).
}

Preparation of graphene can be carried out by four main techniques; $i$ ) chemical vapor deposition, $i$ i) epitaxial growth, iii) mechanical exfoliation of graphite and $i v$ ) chemical synthesis method [8,17-22]. Chemical synthesis method provides an opportunity to prepare graphene through fast and economical mass production approaches [1,2]. This method includes a series of oxidationreduction processes and oxidation of graphite is the most significant stage. Existence of the oxygen functional groups on the graphene oxide (GO) structure make it dispersible in many solvents and allows its utilization in solution processable organic photonic devices [4]. GO can be prepared through four main routes; i.e. Brodie, Hummers, Hoffman and Tour [23-26]. Tour method has been improved by the modification of Hummers method and has significant advantages as it eliminates the generation of toxic gases, reduces the reaction exothermicity and provides higher oxidation yield [26].

In literature, it is generally emphasized that particle size, morphology (powder, flake, expandable), source (neutral or 
synthetic) and reaction conditions of raw graphite influence the properties of obtained GO. To the best of our knowledge, there are only three studies focusing on the influence of particle size of raw graphite on the structure of obtained GO $[1,2,27]$. Botas et al. identified the particle size of graphite as its crystallite size and argued that oxygen functionality and sheet size of obtained GO is influenced by the crystal boundaries in graphite. It was explained that smaller crystallites caused formation of smaller GO sheets and oxidation occurred at the edge sides resulting in carboxylic groups [2]. However, Tran et al. defined that small sized graphite could be easily oxidized and led the formation of higher crystallite structured GO sample. Decrement in GO crystallinity with the increasing raw graphite size was attributed to the damaging of bigger graphite sheets more than the smaller ones during the hard oxidation conditions [27]. Dao et al. agreed with Tran et al. at a certain extend and showed that oxidation degree of GO was increased as the size of raw graphite was reduced [1].

Recently, benefiting from the hydrophilic nature of GO, its utilization in organic light emitting diodes (OLEDs) as dopant in generally used hole injection material (HIM) poly(3,4ethylenedioxythiophene)poly-(styrenesulfonate) (PEDOT:PSS) started to take attention [28-30]. The advantages of GO presence in PEDOT:PSS are described as improving hole transition and decreasing exciton quenching between HIL and emissive layer. It is thought that the particle size of raw graphite would influence the oxidation degree and have an effect on the distribution of oxygen functional groups on GO sheets. These expectations might result in drastic changes on the charge injection and/or accumulation between the HIL and emissive layer. Therefore, in this study, particle size effects of raw graphite $(<150 \mu \mathrm{m}, 45-75 \mu \mathrm{m}$ and $25-45 \mu \mathrm{m})$ on the structural, morphological, optical and electrical properties of obtained GO were investigated. Aqueous dispersions of the synthesized GOs were used to prepare PEDOT:PSS-GO composites and these composites were utilized as HIL of a solution processed blue OLED.

\section{Experimental}

\subsection{Materials}

Expandable graphite powders (Nord-Min 35) was purchased from Nordmann, Rassmann. Potassium permanganate $\left(\mathrm{KMnO}_{4}\right)$, sulfuric acid $\left(\mathrm{H}_{2} \mathrm{SO}_{4}\right)$, phosphoric acid $\left(\mathrm{H}_{3} \mathrm{PO}_{4}\right)$ and hydrogen peroxide $\left(\mathrm{H}_{2} \mathrm{O}_{2}\right)$ were from Merck. Blue emitting polymer, poly[9,9di-(2-ethylhexyl)-fluorenyl-2,7-diyl] end capped with polysilsesquioxane (POSS) (ADS231BE) polymer was bought from American Dye Source. Poly(3,4-ethylenedioxythiophene)poly(styrenesulfonate) (PEDOT:PSS; Al4083) was provided from Ossila. Cesium Carbonate $\left(\mathrm{Cs}_{2} \mathrm{CO}_{3}\right)$ and Aluminum ( $\mathrm{Al}$ ) bought from Sigma-Aldrich. Mica substrates were obtained from SPI (mica grade V-4) and indium thin oxide (ITO; $15 \Omega / \square$ ) was purchased from Lumtec. All the other chemicals were in analytical grade and used as received.

\subsection{Instruments}

Endecotts EFL 2 MK3 Test Sieve Shaker was used to separate the raw graphite in three different size distributions. Preparation of GO dispersion in water was performed by Bandelin Sonoplus HD 2200 Ultrasonic homogenizer. Chemical structures of synthesized GO samples were determined by X-Ray Diffraction [XRD, Rigaku Ultima IV X-Ray Diffractometer using $\mathrm{Cu} \mathrm{K} \alpha$ radiation, data sets were confined in the range of $\left.3-40^{\circ}(2 \theta)\right]$, X-Ray photoelectron spectroscopy (XPS, Thermo Scientific K-Alpha Surface Analysis XPS spectrophotometer), Fourier transform infrared (FT-IR, Perkin
Elmer Spectrum BX FT-IR spectrophotometer with ATR), Thermal gravimetric analysis (TGA, PerkinElmer Pyris 6 TGA) and Raman analysis (Horiba, XploRA) techniques. Optical properties of GO dispersions were characterized by Analytic Jena S600 UV Spectrophotometer. Laurell WS-400B-6NPP-LITE spin coater was used for preparation of the GO and PEDOT:PSS-GO composite thin films. Morphological properties of the GO films were measured by Ambios Q Scope 250 model atomic force microscope (AFM) and for resistivity measurements Signatone PRO4-400 was used. $\mathrm{Cs}_{2} \mathrm{CO}_{3}$ and $\mathrm{Al}$ deposition was performed with a shadow mask by a vacuum evaporator, attached to an MBRAUN 200B glove box system. EL characteristics of the devices were measured by Keithley 2400 source meter and Hamamatsu C10083MD fiber optic spectrophotometer measurement system.

\subsection{Preparation of $\mathrm{GO}$ and $\mathrm{GO}$ thin films}

Raw graphite was sieved to obtain three different particle size distributions of $25-45 \mu \mathrm{m}, 45-75 \mu \mathrm{m}$ and $<150 \mu \mathrm{m}$ and they were identified as G/25-45, G/45-75 and G/150. Oxidation of all graphite materials was carried out by Tour method [26,31]. Shortly summarizing; graphite powder (2.6 g) was oxidized by $\mathrm{KMnO}_{4}(14 \mathrm{~g})$ in the 9:1 mixture of concentrated $\mathrm{H}_{2} \mathrm{SO}_{4} / \mathrm{H}_{3} \mathrm{PO}_{4}(180: 20 \mathrm{ml})$ media at $50{ }^{\circ} \mathrm{C}$ for $15 \mathrm{~h}$. Then reaction mixture was cooled to room temperature (RT) and reaction was terminated by the addition of $30 \%$ $\mathrm{H}_{2} \mathrm{O}_{2}(20 \mathrm{~mL})$ into ice water $(300 \mathrm{~mL})$. Obtained $\mathrm{GO}$ suspension was centrifuged ( $6500 \mathrm{rpm}$ for $1.5 \mathrm{~h}$ ) and supernatant was decanted away. The remaining solid was washed with $200 \mathrm{~mL}$ of $30 \% \mathrm{HCl}$, $200 \mathrm{~mL}$ of ethanol and pure water, respectively. Centrifugation steps were repeated after each washing and water washing process was continued until obtaining neutral pH from decant. Finally, GO solid was vacuum-dried overnight at RT. This procedure was repeated for all of the particle sizes and obtained GO solids were referred as GO/25-45, GO/45-75 and GO/150. Each GO solid was dispersed in pure water and sonicated for $5 \mathrm{~min}$ to obtain homogenous dispersion with four different concentrations i.e. $0.3 \mathrm{mg} /$ $\mathrm{ml}, 1 \mathrm{mg} / \mathrm{ml}, 2 \mathrm{mg} / \mathrm{ml}$ and $8 \mathrm{mg} / \mathrm{ml}$. These dispersions were spin coated at $3000 \mathrm{rpm}$ for $60 \mathrm{~s}$ on mica substrates to investigate concentration effects on morphological properties and surface resistivity of GO thin films.

\subsection{Preparation of PEDOT:PSS-GO composites and their utilization in OLED}

Aqueous dispersion of GO/25-45 GO/45-75 and GO/150 (0.3 mg/ $\mathrm{ml}$ ) were blended with PEDOT:PSS in $1: 1 \mathrm{v} / \mathrm{v}$ ratio, then sonicated for approximately $30 \mathrm{~min}$ to obtained homogenous PEDOT:PSS-GO composites. Prepared composites were termed as PEDOT:PSSGO(25-45), PEDOT:PSS-GO(45-75) and PEDOT:PSS-GO(150). All composites and bare PEDOT:PSS were spin coated on quartz and mica substrates at $3000 \mathrm{rpm}$ and annealed at $100{ }^{\circ} \mathrm{C}$ in vacuum for $30 \mathrm{~min}$. Then optical, sheet resistance and morphological characterizations of the thin films were performed. Sheet resistance values are the mean values of data collected from 20 measurements.

ITO substrates were etched and cleaned by the general method [32,33]. All PEDOT:PSS-GO composites were used as the HIL of the OLED with the structure of ITO/PEDOT:PSS-GO( $\cong 40 \mathrm{~nm})$ / $\operatorname{ADS} 231 \mathrm{BE}(\cong 60 \mathrm{~nm}) / \mathrm{Cs}_{2} \mathrm{CO}_{3}(3 \mathrm{~nm}) / \mathrm{Al}(100 \mathrm{~nm})$. The device prepared by pure water diluted PEDOT:PSS (1:1, v/v ratio) acted as the reference device. The HILs were spin coated at $3000 \mathrm{rpm}$ on the pre-cleaned and oxygen plasma treated ITO substrates and then dried at $100^{\circ} \mathrm{C}$ for $30 \mathrm{~min}$ in vacuum oven. The thicknesses were in the range of $37 \mathrm{~nm}$ and $45 \mathrm{~nm}$. Chlorobenzene solution of ADS231BE (10 mg/mL) was spin-coated onto the HILs at $2500 \mathrm{rpm}$ 
and annealed at $65{ }^{\circ} \mathrm{C}$ for $30 \mathrm{~min}$ in vacuum oven. Finally, $\mathrm{Cs}_{2} \mathrm{CO}_{3}$ $(3 \mathrm{~nm})$ and $\mathrm{Al}(100 \mathrm{~nm})$ were deposited on the active layer by vacuum thermal evaporation $\left(1 \mathrm{E}^{-6}\right.$ torr) system. All electroluminescence (EL) characterizations were executed under nitrogen atmosphere. Four parallel devices with the active areas of $6 \mathrm{~mm}^{2}$ were prepared. The performance results presented here are the mean values.

The procedure described above was repeated for the concentration optimization of GO/150 in PEDOT:PSS. In addition to $0.3 \mathrm{mg} /$ $\mathrm{ml}$ dispersion of GO/150 in water, dispersion concentrations of 0.2 , 0.1 and $0.03 \mathrm{mg} / \mathrm{ml}$ were also used in the preparation of composites and corresponding devices.

\section{Results and discussions}

\subsection{Structural characterization of GO samples}

Fig. 1a represents the XRD patterns of raw graphite samples; $G /$ 25-45, G/45-75 and G/150. In literature, characteristic $2 \theta$ peak of graphite is determined at approximately $26^{\circ}$ from the (002) reflection and that also signify the crystalline size along the c-axis (Lc) $[1,27]$. Lc values and PSD are given in Table S1. A slight improvement in crystallinity was observed for G/25-45 compared to those of G/45-75 and G/150. Interlayer distances (d-spacing) of all samples are obtained as $\sim 3.4 \AA$.

It is known that incorporation of oxygen functionalities to the carbon lattice causes an increment in d-spacing between the layers and shifts the $2 \theta$ peak to lower values [1,34]. After oxidation process, the peak of graphite at $26^{\circ}(2 \theta)$ disappeared completely and new peaks were obtained at $8.80^{\circ}, 10.47^{\circ}$ and $10.58^{\circ}$ for $\mathrm{GO} / 25-45$, GO/45-75 and GO/150, respectively (Fig. 1 b). GO/25-45 presented a sharper and more shifted XRD peak than GO/45-75 and GO/150 and interlayer distances (d-spacing) of GO/25-45, GO/45-75 and GO/150 were determined as $10.00,8.46$ and $8.36 \AA$, respectively. Approximately 3 -fold of increment in d-spacing of GO samples compared to that of raw graphite samples points out that incorporation of oxygen functional groups into the carbon lattice was successfully achieved [34,35]. It is assumed that obtaining higher d-spacing for GO/25-45 may be the result of more hydroxyl, epoxy and carbonyl group formations on the basal plane and this assumption is confirmed by the XPS results. This functionality may lead uniformly ordered crystalline structures for $\mathrm{GO} / 25-45$ whereas for $\mathrm{GO} / 45-75$ and GO/150 samples, steric effects of carboxylic acid groups on the edge sides may have inhibited uniform arrangement. It can be concluded that particle size of raw graphite play a key role in the dominant oxidation region and consequently d-spacing of the obtained GO.

Fig. 2 shows XPS general spectra and curve fit of C1s spectra of $\mathrm{GO} / 25-45, \mathrm{GO} / 45-75$ and $\mathrm{GO} / 150$ samples. All of them have a broad
C 1s peak that is convoluted into five characteristic sub peaks between 283 and $290 \mathrm{eV}$. The peaks centered at around 283.7, 284.6, 285.6, 287.1 and $288.9 \mathrm{eV}$ corresponds to the $\mathrm{sp}^{3}$ carbon $(\mathrm{C}-\mathrm{C}), \mathrm{sp}^{2}$ carbon $(\mathrm{C}=\mathrm{C})$, hydroxyl and epoxy $(\mathrm{C}-\mathrm{O})$, carboxyl $(\mathrm{C}=\mathrm{O})$ and carboxylic acid groups $(\mathrm{O}=\mathrm{C}-\mathrm{O})$, respectively. Existence of these functional groups is compatible with the FT-IR spectra (Fig. 3). Stretching peaks of $\mathrm{O}-\mathrm{H}\left(\sim 3400 \mathrm{~cm}^{-1}\right), \mathrm{C}-\mathrm{OH}\left(1039 \mathrm{~cm}^{-1}\right), \mathrm{C}-\mathrm{O}-\mathrm{C}$ $\left(\sim 1200 \mathrm{~cm}^{-1}\right), \mathrm{C}=\mathrm{O}\left(1720 \mathrm{~cm}^{-1}\right)$ and $\mathrm{O}=\mathrm{C}-\mathrm{O}\left(\sim 1373 \mathrm{~cm}^{-1}\right)$ oxygenated functional groups and un-oxidized graphitic $\mathrm{C}=\mathrm{C}$ bonds $(\sim 1622 \mathrm{~cm}-1)$ are monitored in all GO samples.

Abundance of (A\%) functional groups on the GO samples differed depending on the particle size of raw graphite and oxidation degree values are slightly reduced with the decreasing particle size. A maximum of $\mathrm{C}-\mathrm{O}$ groups determined for $\mathrm{GO} / 25-45$, whereas $\mathrm{C}=\mathrm{O}$ and $\mathrm{C}(\mathrm{O}) \mathrm{OH}$ groups were exhibited a max. value for $\mathrm{GO} / 45-75$ and $\mathrm{GO} / 150$, respectively (Table 1 ). This can be explained by the oxidation mechanism of graphite. Concentrated $\mathrm{H}_{2} \mathrm{SO}_{4}$ generates electrophilic $\mathrm{SO}_{3}$, given as follows;

$$
2 \mathrm{H}_{2} \mathrm{SO}_{4} \rightleftarrows \mathrm{SO}_{3}+\mathrm{H}_{3} \mathrm{O}^{+}+\mathrm{HSO}_{4}^{-}
$$

According to given equation, two expected interactions may occur between graphene and $\mathrm{H}_{2} \mathrm{SO}_{4} ; i$ ) electrophilic $\mathrm{SO}_{3}$ may attack to graphene layers as benzene sulfonation approach [36] and ii) $\mathrm{H}_{2} \mathrm{SO}_{4} / \mathrm{HSO}_{4}^{-}$may attach to the intrinsic defects of raw graphite [37]. These interactions lead the expansion of layers for penetration of the oxidizing agent $\left(\mathrm{KMnO}_{4}\right)[37,38]$. It has been already identified that substitution reaction between $\mathrm{H}_{2} \mathrm{SO}_{4}$ (attached onto graphene layers) and $\mathrm{KMnO}_{4}$ can be the key factor for the oxidation of graphite. During this process vicinal diols are firstly occurred via formation of manganite esters. Thereafter, some part of these diols converts into epoxy groups $(\mathrm{C}-\mathrm{O}-\mathrm{C})$ while some of them were oxidized to two adjacent ketone groups. According to the literature explanations it could be implied that oxidation is occurred at edge first and then on the activated defect sides of basal plane for all GO sources [37]. Higher $\mathrm{O}=\mathrm{C}-\mathrm{O} \%$ and lower $\mathrm{C}-\mathrm{O} \%$ values obtained for $\mathrm{GO} / 45-75$ and $\mathrm{GO} / 150$ than those of $\mathrm{GO} / 25-45$ are attributed to more edge side oxidations as a result of the slower diffusion rate of $\mathrm{KMnO}_{4}$ and lower amount of hydroxyl and epoxy protecting $\mathrm{H}_{3} \mathrm{PO}_{4}$ per unit area of GO in larger particles. It can be concluded that unlike the literature explanation [1,27], decrement in particle size of raw graphite caused a slight reduction in the oxidation degree. This could be explained by the bigger lateral size of GO/25-45 compared to others, that is confirmed by the morphological results. Additionally, particle size had a dramatic effect on the distribution of oxygen functional groups on GO sheets which may help the choice of appropriate modification chemical for its utilization in various application areas.

TGA results of GO samples are given in Fig. S1. It has been
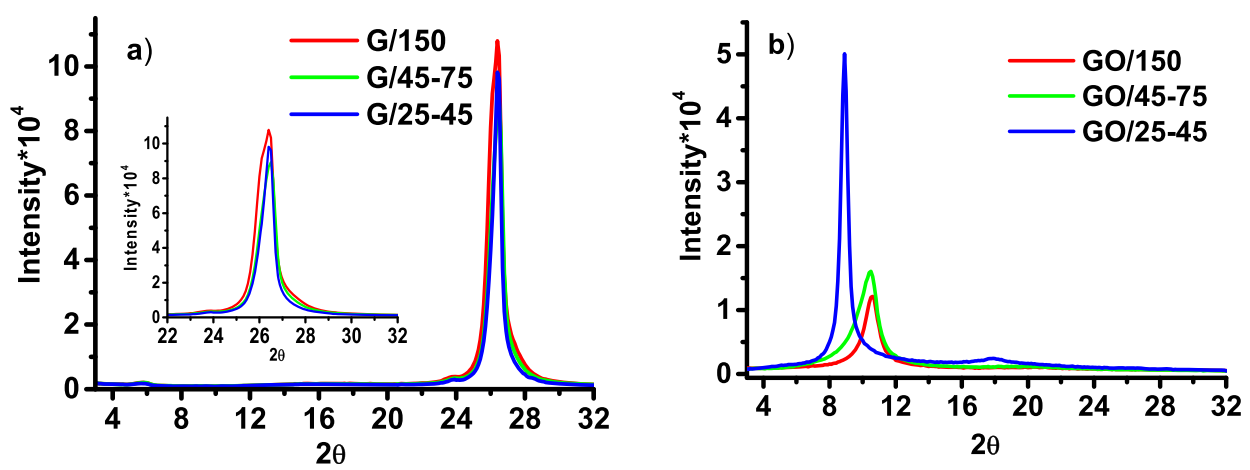

Fig. 1. XRD pattern of a) raw graphite samples (inset: magnification of the corresponding curve for $22-32^{\circ} 2 \theta$ ), b) GO samples. 

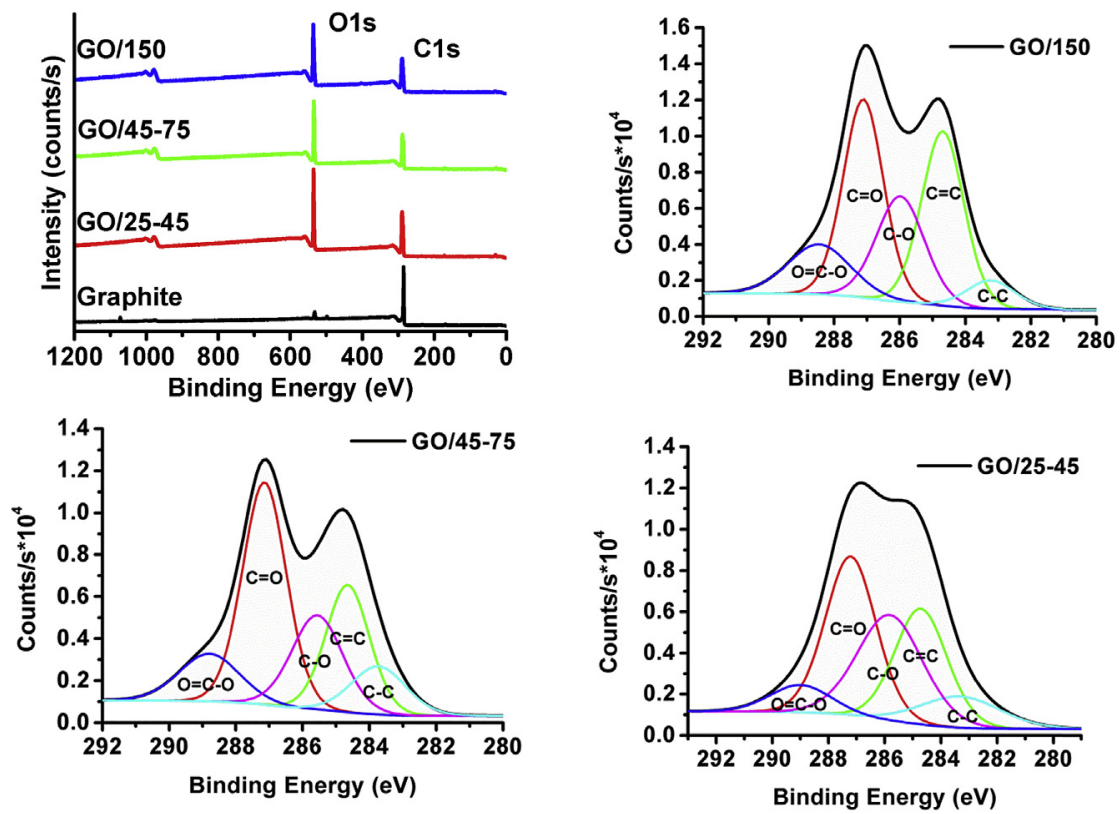

Fig. 2. XPS general spectra and curve fit of C1s spectra of all GO samples.

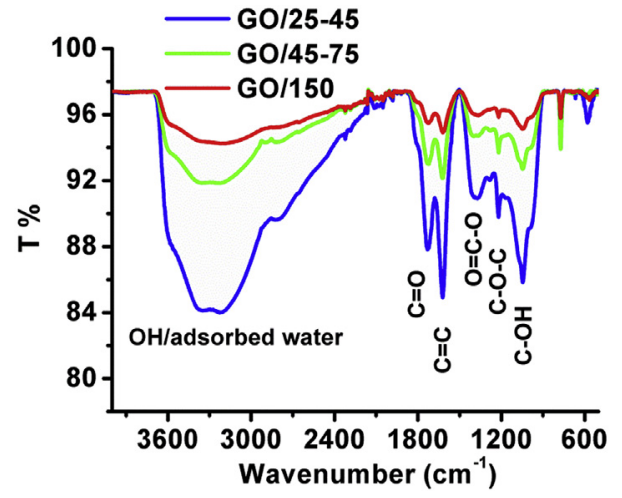

Fig. 3. FT-IR spectrum of GO samples.

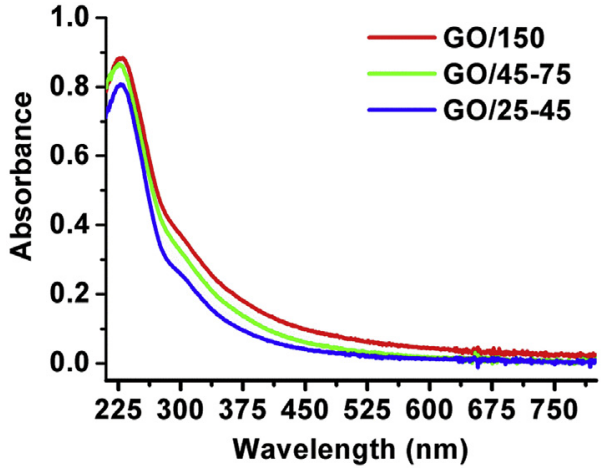

Fig. 4. UV-VIS absorption spectrum of GO/150, GO/45-75 and GO/25-45 samples.

Table 1

Distributions of atomic percentages (A \%) of functional groups.

\begin{tabular}{|c|c|c|c|c|c|c|}
\hline \multirow[t]{2}{*}{ Sample } & \multicolumn{5}{|l|}{$\mathrm{C} 1 \mathrm{~s} \%$} & \multirow[t]{2}{*}{$\mathrm{O} / \mathrm{C}$} \\
\hline & $\mathrm{sp}^{3} \mathrm{C}-\mathrm{C}$ & $\mathrm{sp}^{2} \mathrm{C}=\mathrm{C}$ & $\mathrm{C}-\mathrm{O}(\mathrm{OH} / \mathrm{epoxy})$ & $\mathrm{C}=\mathrm{O}$ (ketone/quinone) & $\mathrm{O}=\mathrm{C}-\mathrm{O}($ carboxyl $)$ & \\
\hline $\mathrm{GO} / 25-45$ & 9.81 & 24.03 & 27.47 & 32.04 & 6.65 & 0.44 \\
\hline $\mathrm{GO} / 45-75$ & 10.18 & 21.62 & 18.83 & 38.10 & 11.27 & 0.47 \\
\hline GO/150 & 5.47 & 29.44 & 20.36 & 32.06 & 12.67 & 0.49 \\
\hline
\end{tabular}

identified that significant mass loss at about $200{ }^{\circ} \mathrm{C}$ was related to pyrolysis of the unstable oxygen functional groups, especially hydroxyl groups, in the GO structure [1]. The highest total mass loss between 190 and $230{ }^{\circ} \mathrm{C}$ was detected for GO/25-45 (45.70\%) that may be attributed to the more $\mathrm{C}-\mathrm{O} \%$ of this sample.

\subsection{Optical, sheet resistance and morphological characterization of GO}

UV-VIS spectra of all GO samples are illustrated in Fig. 4. The main absorption peak at $230 \mathrm{~nm}$ is attributed to $\pi \rightarrow \pi^{*}$ transition of the $\mathrm{C}=\mathrm{C}$ bond and the small shoulder at around $300 \mathrm{~nm}$ is related to $\mathrm{n} \rightarrow \pi^{*}$ transition of non-bonding electrons of oxygen functionalities.

AFM is the most useful technique to investigate the lateral size and sheet thickness of GO samples. It was interesting to observe that decrement in particle size of raw graphite slightly increased the lateral sizes of finally obtained GO sheets (Fig. 5). This morphological determination was supported with the XPS results discussed above; existence of more carboxylic acid groups in $\mathrm{GO} /$ 45-75 and GO/150 samples may be the result of smaller GO sheet formation. Concentration of the dispersion which is used in the film formation is one of the important parameters to observe single layer GO on the surface. Therefore, GO thin films were prepared by 


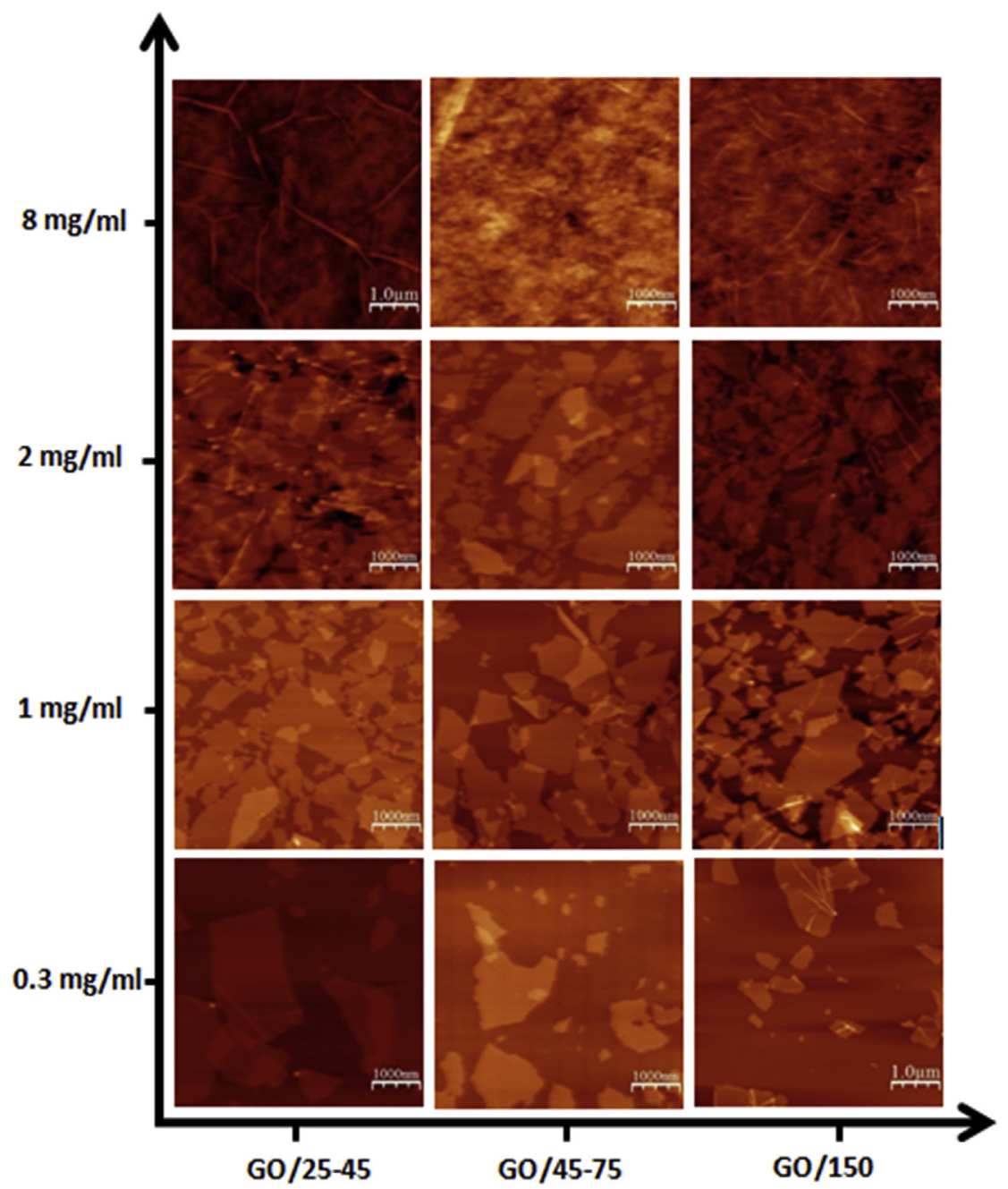

Fig. 5. AFM images of GO/25-45, GO/45-75 and GO/150 films on mica surface different dispersion concentration.

$\mathrm{GO} / 25-45, \mathrm{GO} / 45-75$ and $\mathrm{GO} / 150$ dispersions from four different concentrations i.e. $0.3 \mathrm{mg} / \mathrm{ml}, 1 \mathrm{mg} / \mathrm{ml}, 2 \mathrm{mg} / \mathrm{ml}$ and $8 \mathrm{mg} / \mathrm{ml}$. Single layered GO sheets could be observed for all GO films which were prepared from the most diluted dispersion $(0.3 \mathrm{mg} / \mathrm{ml})$ (Fig. 5).

It is known that although single layered graphene is an excellent conductive material, GO behaves mostly as an insulator and has a heterogeneous electronic structure due to its both $\mathrm{sp}^{2}$ and $\mathrm{sp}^{3}$ hybridization and presence of oxygen functional groups. However, lateral conductivity of GO has been mentioned by considering the hopping mechanism between $\mathrm{sp}^{2}$ clusters $[4,39]$. Although the lateral size of $\mathrm{GO} / 25-45$ was slightly higher than that of $\mathrm{GO} / 45-75$ and $\mathrm{GO} / 150$, the $\mathrm{GO} / 25-45$ film presented smaller conductivity for both $1 \mathrm{mg} / \mathrm{ml}$ and $2 \mathrm{mg} / \mathrm{ml}$ concentrations (Fig. 6). This is attributed to the existence of more hydroxyl/epoxy groups on basal plane of GO/25-45 which may have disturbed the hopping between $\mathrm{sp}^{2}$ conjugated carbons. Further increment in the dispersion concentration $(8 \mathrm{mg} / \mathrm{ml})$ caused formation of thick and bulky structured GO sheets (Fig. 5) and as expected, a dramatic decrement in conductivity of the films. Independent from the particle size, these thick films have approximately similar conductivity values. The conductivity values of the films which were prepared from $0.3 \mathrm{mg} /$ $\mathrm{ml} \mathrm{GO}$ dispersions are not discussed here because of misleading results generating from the full surface coverage problem of this concentration.

\subsection{Characterization of PEDOT:PSS-GO composites and performance results of their OLED devices}

Sheet resistance of bare PEDOT:PSS, PEDOT:PSS-GO(25-45), PEDOT:PSS-GO(45-75) and PEDOT:PSS-GO(150) were measured as $806 \pm 338,30 \pm 5,39 \pm 8$ and $26 \pm 9 \mathrm{M} \Omega /$, respectively and no

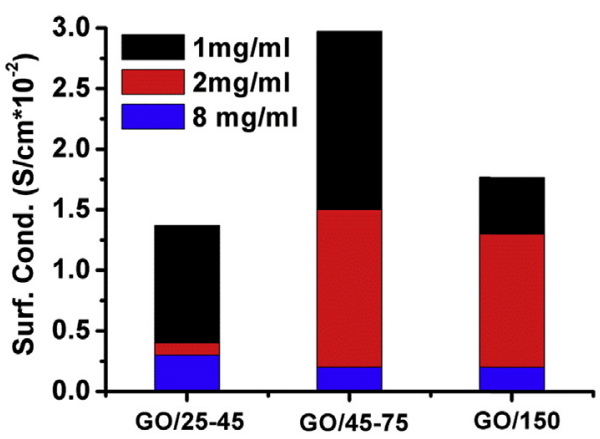

Fig. 6. Surface conductivity of GO thin films with different dispersion concentration. 
b)

$\mathrm{E}=0$ Vacuum Level
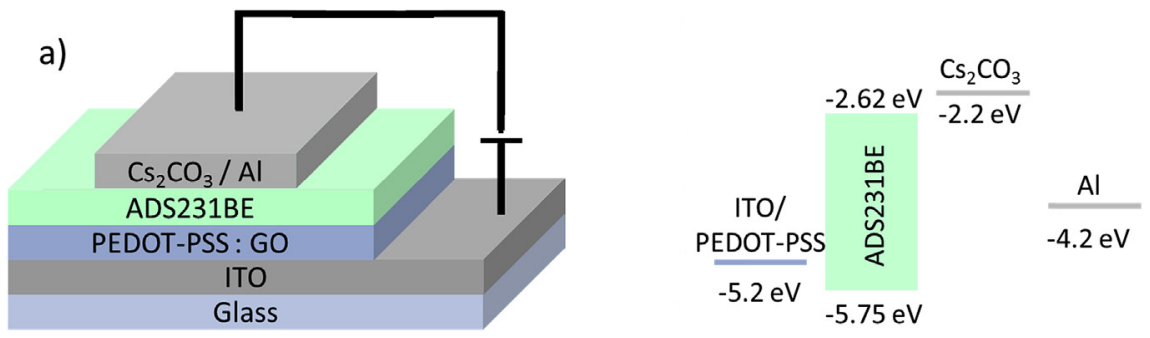

Fig. 7. a) OLED structure and b) Energy band diagram.

deviation from the resistance value of PEDOT:PSS-GO/150 was detected depending on the GO concentration. Decrement in sheet resistance of PEDOT:PSS-GO composites compared to bare PEDOT:PSS may be attributed to the benzoid-quinoid transitions of PEDOT [40]. It is thought that GO interacts with PEDOT via $\pi-\pi$ stacking and hydrogen bonding due to the oxygen functional groups on GO and stimulates the quinoidal form of PEDOT. No significant influence of this resonance transition, induced with the presence of GO in PEDOT:PSS, on the surface morphology is detected (Fig. S2)

Transmittance curves of all composites are presented in Fig. S3. The values corresponding to $420 \mathrm{~nm}$ (the EL maximum of the blue OLED studied in this manuscript), $555 \mathrm{~nm}$ (the maximum spectral sensitivity of the human eye under daylight conditions) and $\Delta \mathrm{T}$ values for the visible range are all determined to be higher than 95\%. As expected, the presence of GO in PEDOT:PSS did not cause a significant deviation as the concentration of GO in composites is very low and the film thicknesses were approximately the same with the bare PEDOT:PSS film.

The device structure of the OLED and energy band diagram is shown in Fig. 7 and the performance curves of devices are given in Fig. 8 and Fig. S4. Light emissions of all the devices were in the blue area. Although small deviations are observed due to the doping of GO and depending on the applied voltage, the CIE coordinates of all devices were determined to be $0.18 ; 0.18(\mathrm{x} ; \mathrm{y})$ at the maximum applied voltage. The device with the HIL of PEDOT:PSS-GO/150 presented the best performance. The luminous and external quantum efficiency values of this device were more than $40 \%$ and $50 \%$ higher than that of the reference, respectively. The performance values were able to be increased to $0.17 \mathrm{~cd} / \mathrm{A}, 0.11 \mathrm{~lm} / \mathrm{W}$ and $0.11 \%$ in the device that was prepared by the use of $0.1 \mathrm{mg} / \mathrm{ml} \mathrm{GO} /$ 150 in HIL. However, presence of GO in HIL caused an increase in the turn-on voltage, NDR characteristics between the applied voltages of $2.5-5.5 \mathrm{~V}$ and leakage currents up to $200 \mathrm{~mA}$. Decreasing the concentration of GO/150 in PEDOT:PSS, resulted in a reduction in NDR intensities and current leakages. No efficiency could be detected at the NDR area. These findings are attributed to the $p$-type character of ADS231BE and low lying work function of GO $[15,28,30,41]$ which compose a potential barrier between the HIL and emission layer for the injection of holes, in other words extraction of electrons.

An increase in the NDR effect with the decrease in particle size of graphite used in the synthesis of GO is detected. The increase in lateral size (Fig. 5) may have favored charge accumulation and therefore increased the NDR character. As discussed earlier, although slight deviations were obtained on the total population of oxygen functionalities with the particle size of raw graphite, the lateral sizes and chemical natures of the obtained GO are affected.
The change in chemical nature has an influence on the electron affinity and it may have an effect on the hole injection into the emission layer. It is known that $\mathrm{sp}^{2}$ hybridized carbon atoms are more electronegative and the electronegativity of the carbon in $\mathrm{C}=$ $\mathrm{O}$ bond is much higher than the one in $\mathrm{C}=\mathrm{C}$. As the carbonyls are placed on the basal plane and the carboxyls are at the edges, it is easier for the carboxyls to except electrons. The A\% of carboxyl function group increases with the order of GO/25-45 $<\mathrm{GO} / 45$ $75<\mathrm{GO} / 150$ (Table 1 ), which is the inverse order of NDR characteristics and current losses observed in current density-voltage and efficiency curves, respectively (Fig. 8).

As stated above, decreasing the GO concentration in the HIM, constantly reduced the NDR intensity and current leakages. Although all performance values were better than the reference device, the efficiency increment was obtained up to $0.1 \mathrm{mg} / \mathrm{ml} \mathrm{GO} /$ 150 and further decrement in the amount of GO/150 in HIM reduced the efficiency values. The results suggest that not only the energy levels but also the number of electron accepting functionalities in HIM were optimized at this concentration and this is supported by all performance data including the current density values at $100 \mathrm{~cd} / \mathrm{m}^{2}$ reported in Table 2 .

\section{Conclusion}

Effects of raw graphite's particle size on the properties of obtained GO were investigated systematically. The particle size of raw graphite has an impact on the oxidation degree and the formation of decisive oxygen functional group on the GO. It was determined that maximum $\mathrm{C}-\mathrm{O}$ groups existed on $\mathrm{GO} / 25-45$, whereas $\mathrm{C}=0$ and $\mathrm{C}(\mathrm{O}) \mathrm{OH}$ groups were the dominant functional groups on $\mathrm{GO} /$ 45-75 and GO/150, respectively. Different densities of oxygen functionalities on each GOs may help the choice of appropriate modification chemical for its utilization in various application areas. Independent from the particle size of starting graphite, increasing the stock dispersion concentration used in the preparation of film, led the formation of bulky structured GO films and caused a decrement in lateral conductivity. Starting from larger graphite samples resulted in smaller lateral size of GOs. Although the morphology is not effected, sheet resistance of PEDOT:PSS is reduced with the presence of GO. Transmittance of all composites was above $95 \%$. These composites are utilized as the HIL of a solution processed blue OLED and an increase in the NDR behavior was observed with the decrease in starting particle size of raw graphite. All performance values obtained were better than the reference device. This situation is attributed to not only the potential barrier increase between the HIL and $p$-type emission layer but also to the population of carboxyl function groups on the GO. 

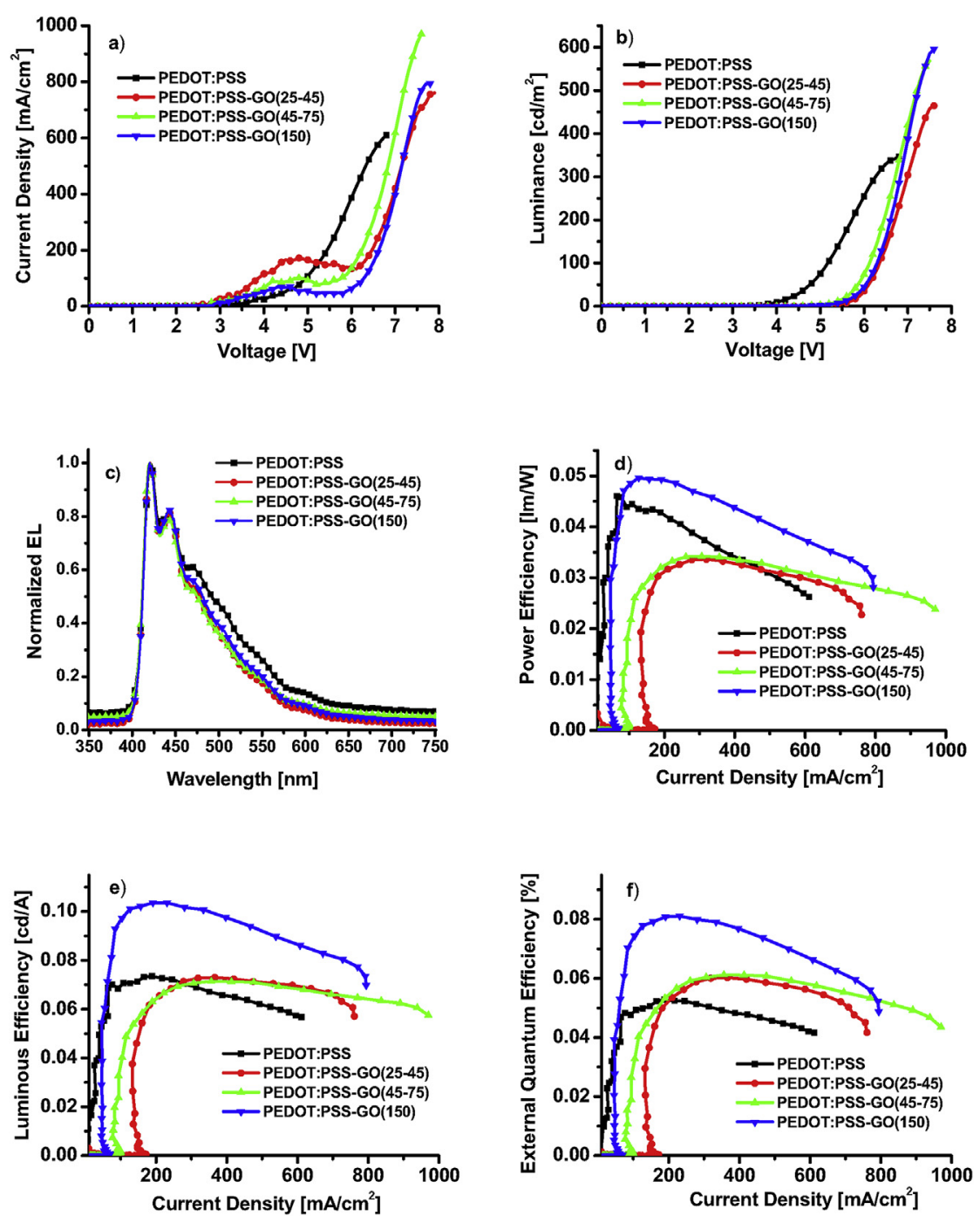

Fig. 8. a) Current Density - Voltage, b) Luminance - Voltage, c) Normalized EL - Wavelength, d) Power Efficiency - Current Density, e) Luminous Efficiency - Current Density, f) EQE - Current Density curves of ITO/PEDOT:PSS-GO(0.3 mg/ml)/ADS231 BE $/ \mathrm{Cs}_{2} \mathrm{CO}_{3} / \mathrm{Al}$ devices.

Table 2

ITO/PEDOT:PSS-GO(150)(x mg/ml)/ADS231BE/ $\mathrm{Cs}_{2} \mathrm{CO}_{3} / \mathrm{Al}$ device's performance at $100 \mathrm{~cd} / \mathrm{m}^{2}$ (Values are extracted from Fig. 8 and Fig. S4).

\begin{tabular}{|c|c|c|c|c|c|}
\hline PEDOT:PSS-GO (x mg/ml) & Working Voltage [V] & Current Density $\left[\mathrm{mA} / \mathrm{cm}^{2}\right]$ & Luminous Efficiency [cd/A] & Power Efficiency [lm/W] & External Quantum Efficiency (\%) \\
\hline PEDOT-PSS: 0 & 5.1 & 142 & 0.071 & 0.043 & 0.051 \\
\hline PEDOT-PSS: 0.3 & 6.3 & 103 & 0.097 & 0.048 & 0.074 \\
\hline PEDOT-PSS: 0.2 & 6.0 & 90 & 0.111 & 0.058 & 0.074 \\
\hline PEDOT-PSS: 0.1 & 6.1 & 64 & 0.156 & 0.080 & 0.102 \\
\hline PEDOT-PSS: 0.03 & 5.5 & 81 & 0.123 & 0.070 & 0.084 \\
\hline
\end{tabular}

\section{Acknowledgements}

This work was supported by the research project funds of Scientific Research Council of Turkey (TUBITAK) (Project \#: 114M508).

\section{Appendix A. Supplementary data}

Supplementary data related to this article can be found at http:// dx.doi.org/10.1016/j.cap.2017.02.002.

\section{References}

[1] T.D. Dao, H.M. Jeong, Graphene prepared by thermal reduction - exfoliation of graphite oxide: effect of raw graphite particle size on the properties of graphite oxide and graphene, Mater. Res. Bull. 70 (2015) 651-657, http:// dx.doi.org/10.1016/j.materresbull.2015.05.038.

[2] C. Botas, P. Álvarez, C. Blanco, R. Santamaria, M. Granda, P. Ares, F. RodriguezReinoso, R. Menéndez, The effect of the parent graphite on the structure of graphene oxide, Carbon N. Y. 50 (2012) 275-282, http://dx.doi.org/10.1016/ j.carbon.2011.08.045.

[3] Q. Liu, Z. Liu, X. Zhang, N. Zhang, L. Yang, S. Yin, Y. Chen, Organic photovoltaic cells based on an acceptor of soluble graphene, Appl. Phys. Lett. 92 (2008) 3-5, http://dx.doi.org/10.1063/1.2938865.

[4] H.S. Dehsari, E.K. Shalamzari, J.N. Gavgani, F.A. Taromi, S. Ghanbary, Efficient preparation of ultralarge graphene oxide using a PEDOT: PSS/GO composite layer as hole transport layer in polymer-based optoelectronic devices, RSC Adv. 4 (2014) 55067-55076, http://dx.doi.org/10.1039/C4RA09474C.

[5] X.-Z. Zhu, Y.-Y. Han, Y. Liu, K.-Q. Ruan, M.-F. Xu, Z.-K. Wang, J.-S. Jie, L.-S. Liao, The application of single-layer graphene modified with solution-processed 
TiOx and PEDOT: PSS as a transparent conductive anode in organic lightemitting diodes, Org. Electron 14 (2013) 3348-3354, http://dx.doi.org/ 10.1016/j.orgel.2013.10.003.

[6] Y. Gao, H. Yip, K. Chen, K.M. O'Malley, O. Acton, Y. Sun, G. Ting, H. Chen, A.K.Y. Jen, Surface doping of conjugated polymers by graphene oxide and its application for organic electronic devices, Adv. Mater. 23 (2011) 1903-1908, http://dx.doi.org/10.1002/adma.201100065.

[7] F. Bonaccorso, Z. Sun, T. Hasan, A.C. Ferrari, Graphene photonics and optoelectronics, Nat. Photonics 4 (2010) 611-622, http://dx.doi.org/10.1038/ nphoton.2010.186.

[8] T. Kuila, A.K. Mishra, P. Khanra, N.H. Kim, J.H. Lee, Recent advances in the efficient reduction of graphene oxide and its application as energy storage electrode materials, Nanoscale 5 (2013) 52-71, http://dx.doi.org/10.1039/ c2nr32703a.

[9] H. Ha, O. Kim, Bipolar switching characteristics of nonvolatile memory devices based on poly ( 3,4- ethylenedioxythiophene ): poly ( styrenesulfonate ) thin film, Appl. Phys. Lett. 93 (2008) 33309, http://dx.doi.org/10.1063/1.2960998.

[10] L.L. Zhang, R. Zhou, X.S. Zhao, Graphene-based materials as supercapacitor electrodes, J. Mater. Chem. 20 (2010) 5983-5992, http://dx.doi.org/10.1039/ c000417k.

[11] T. Kuila, S. Bose, P. Khanra, K.A. Mishra, N.H. Kim, J.H. Lee, Recent advances in graphene-based biosensors, Biosens. Bioelectron. 26 (2011) 4637-4648, http://dx.doi.org/10.1016/j.bios.2011.05.039.

[12] Y.-P. Hsieh, C.-H. Yen, P.-S. Lin, S.-W. Ma, C.-C. Ting, C.-I. Wu, M. Hofmann, Ultra-high sensitivity graphene photosensors, Appl. Phys. Lett. 104 (2014) 41110, http://dx.doi.org/10.1063/1.4863441.

[13] N. Mahmood, C. Zhang, H. Yin, Y. Hou, Graphene-based nanocomposites for energy storage and conversion in lithium batteries, supercapacitors and fuel cells, J. Mater. Chem. A 2 (2014) 15-32, http://dx.doi.org/10.1039/c3ta13033a.

[14] B.F. Machado, P. Serp, Graphene-based materials for catalysis, Catal. Sci. Technol. 2 (2012) 54-75, http://dx.doi.org/10.1039/c1cy00361e.

[15] P.J. Jesuraj, R. Parameshwari, K. Kanthasamy, J. Koch, H. Pfnür, K. Jeganathan, Hole injection enhancement in organic light emitting devices using plasma treated graphene oxide, Appl. Surf. Sci. 397 (2017) 144-151, http://dx.doi.org/ 10.1016/j.apsusc.2016.11.110.

[16] S. Bak, D. Kim, H. Lee, Graphene quantum dots and their possible energy applications: a review, Curr. Appl. Phys. 16 (2016) 1192-1201, http:// dx.doi.org/10.1016/j.cap.2016.03.026.

[17] A. Reina, X. Jia, J. Ho, D. Nezich, H. Son, V. Bulovic, M.S. Dresselhaus, J. Kong, Large area, few-layer graphene films on arbitrary substrates by chemical vapor deposition, Nano Lett. 9 (2009) 30-35, http://dx.doi.org/10.1021/ nl801827v.

[18] K.S. Novoselov, A.K. Geim, S. Morozov, D. Jiang, Y. Zhang, S.V. Dubonos, I.V. Grigorieva, A.A. Firsov, Electric field effect in atomically thin carbon films, Science 306 (2004) 666-669, http://dx.doi.org/10.1126/science.1102896 (80-. ).

[19] Z. Wu, W. Ren, L. Gao, B. Liu, C. Jiang, H. Cheng, Synthesis of high-quality graphene with a pre-determined number of layers, Carbon N. Y. 47 (2009) 493-499, http://dx.doi.org/10.1016/j.carbon.2008.10.031.

[20] W. Fu, J. Kiggans, S.H. Overbury, V. Schwartz, C. Liang, Low-temperature exfoliation of multilayer-graphene material from $\mathrm{FeCl} 3$ and $\mathrm{CH} 3 \mathrm{NO} 2$ cointercalated graphite compound, Chem. Commun. 47 (2011) 5265-5267, http://dx.doi.org/10.1039/c1cc10508f.

[21] S. Stankovich, D.A. Dikin, R.D. Piner, K.A. Kohlhaas, A. Kleinhammes, Y. Jia, Y. Wu, S.T. Nguyen, R.S. Ruoff, Synthesis of graphene-based nanosheets via chemical reduction of exfoliated graphite oxide, Carbon N. Y. 45 (2007) 1558-1565, http://dx.doi.org/10.1016/j.carbon.2007.02.034.

[22] H. Tetlow, J.P. De Boer, I.J. Ford, D.D. Vvedensky, J. Coraux, L. Kantorovich, Growth of epitaxial graphene: theory and experiment, Phys. Rep. 542 (2014)
195-295, http://dx.doi.org/10.1016/j.physrep.2014.03.003.

23] B.C. Brodie, On the atomic weight of graphite, Philos. Trans. R. Soc. Lond. 149 (1859) 249-259, http://dx.doi.org/10.1016/0039-9140(69)80013-5.

[24] W.S. Hummers Jr., R.E. Offeman, Preparation of graphitic oxide, J. Am. Chem. Soc. 80 (1958) 1339, http://dx.doi.org/10.1021/ja01539a017, 1339.

[25] N.I. Kovtyukhova, P.J. Ollivier, B.R. Martin, T.E. Mallouk, S.A. Chizhik E.V. Buzaneva, A.D. Gorchinskiy, Layer-by-Layer assembly of ultrathin composite films from micron-sized graphite oxide sheets and polycations, Chem. Mater. 11 (1999) 771-778, http://dx.doi.org/10.1021/cm981085u.

[26] D.C. Marcano, D. V Kosynkin, J.M. Berlin, A. Sinitskii, Z.Z. Sun, A. Slesarev, L.B. Alemany, W. Lu, J.M. Tour, Improved synthesis of graphene oxide, ACS Nano 4 (2010) 4806-4814, http://dx.doi.org/10.1021/nn1006368.

[27] M.H. Tran, C.S. Yang, S. Yang, I.J. Kim, H.K. Jeong, Influence of graphite size on the synthesis and reduction of graphite oxides, Curr. Appl. Phys. 14 (2014) S74-S79, http://dx.doi.org/10.1016/j.cap.2013.11.038.

[28] C.C.H. Lin, K. Chen, J.R.J. Ho, J.-W.J. Cheng, R.C.C.C. Tsiang, PEDOT: PSS/Graphene nanocomposite hole-injection layer in polymer light-emitting diodes, J. Nanotechnol. 2012 (2012) 1-7, http://dx.doi.org/10.1155/2012/942629.

[29] J.C. Yu, J.I. Jang, B.R. Lee, G.W. Lee, J.T. Han, M.H. Song, highly efficient polymer-based optoelectronic devices using PEDOT: PSS and a GO composite layer as a hole transport layer, Appl. Mater. Interfaces 6 (2014) 2067-2073. http://dx.doi.org/10.1021/am4051487.

[30] D. Kim, D. Lee, Y. Lee, D.Y. Jeon, Work-function engineering of graphene anode by bis(trifluoromethanesulfonyl)amide doping for efficient polymer lightemitting diodes, Adv. Funct. Mater. 23 (2013) 5049-5055, http://dx.doi.org/ 10.1002/adfm201301386.

[31] J.M. Tour, D. V Kosynkin, United States Patent Application Publication, US 2012/0129736 A1, 2012

[32] N. Demir, I. Oner, C. Varlikli, C. Ozsoy, C. Zafer, Efficiency enhancement in a single emission layer yellow organic light emitting device: contribution of CIS ZnS quantum dot, Thin Solid Films 589 (2015) 153-160, http://dx.doi.org/ 10.1016/j.tsf.2015.05.006.

[33] G. Saygili, C. Varlikli, C. Zafer, C. Ozsoy, Highly efficient MEH-PPV-POSS based PLEDs through optimization of charge transport, Synth. Met. 162 (2012) 621-629, http://dx.doi.org/10.1016/j.synthmet.2012.02.010.

[34] M. Wojtoniszak, X. Chen, R.J. Kalenczuk, A. Wajda, J. Łapczuk, M. Kurzewski, M. Drozdzik, P.K. Chu, E. Borowiak-Palen, Synthesis, dispersion, and cytocompatibility of graphene oxide and reduced graphene oxide, Colloids Surf. B $\begin{array}{lllll}\text { Biointerfaces } & 89 & \text { (2012) 79-85, http://dx.doi.org/10.1016/ }\end{array}$ j.colsurfb.2011.08.026.

[35] J. Leffler, Towards Graphene Based Transparent Conductive Coating, Luleå University, 2012.

[36] G. Solomons, C. Fryhle, Organic Chemistry, seventh ed., John Willey \& Sons Inc., 2000.

[37] G. Shao, Y. Lu, F. Wu, C. Yang, F. Zeng, Q. Wu, Graphene oxide: the mechanisms of oxidation and exfoliation, J. Mater. Sci. 47 (2012) 4400-4409, http:// dx.doi.org/10.1007/s10853-012-6294-5.

[38] A.M. Dimiev, J.M. Tour, Mechanism of graphene oxide formation, ACS Nano 8 (2014) 3060-3068, http://dx.doi.org/10.1021/nn500606a.

[39] S.-S. Li, K.-H. Tu, C.-C. Lin, C.-W. Chen, M. Chhowalla, Solution-processable graphene oxide as an efficient hole transport layer in polymer solar cells, ACS Nano 4 (2010) 3169-3174, http://dx.doi.org/10.1021/nn100551j.

[40] V.C. Tung, J. Kim, L.J. Cote, J. Huang, Sticky interconnect for solution-processed tandem solar cells, J. Am. Chem. Soc. 133 (2011) 9262-9265, http:/ dx.doi.org/10.1021/ja203464n.

[41] N. Demir, Photophysical Behavior Investigations and OLED Applications of Blue and Yellow Emitting Polymer- CuInS2 Quantum Dot Hybrids, Ege University, 2014. 